\title{
Emergencies in Cardiovascular Surgery- A Clinical Judgment and Treatment Strategy
}

\author{
Tanja Anguseva ${ }^{1 *}$, Zan Mitrev $^{2}$ \\ ${ }^{1}$ Intensive Care Unit, Special Hospital Zan Mitrev Clinic, Macedonia \\ ${ }^{2}$ Surgery Department, Special Hospital Zan Mitrev Clinic, Macedonia
}

"Corresponding author: Tanja Anguseva, Intensive care unit, Special Hospital Zan Mitrev Clinic, Str. Bledski Dogovor \#81000 Skopje, Macedonia. Tel: +38923091500, Fax:+38923104947; Email: tanja.anguseva@filipvtori.com

Citation: Anguseva T, Mitrev Z (2017) Emergencies in Cardiovascular Surgery- A Clinical Judgment and Treatment Strategy. Cardiolog Res Cardiovasc Med 2: 119. DOI: 10.29011/2575-7083.000019

Received Date: 23 June, 2017; Accepted Date: 23 September, 2017; Published Date: 30 September, 2017

\begin{abstract}
Urgent surgery is part of a daily practice on cardiovascular units, and it may be required in patients with conditions such as acute coronary syndrome, endocarditis and valvular diseases, trauma, acute aortic dissection as well as Acute Vascular embolization's and Leriche Syndrome.

In emergency situation, preoperative patient work-up for cardio-vascular surgery is quite different from the elective setting. Since 03/2000 till 01/2012 we have analyzed a consecutive series of 10023 cases out of which 1823 underwent emergency procedures $(18.19 \%)$. The most frequent problems requiring urgent intervention were thoracic aortic aneurysms (369 cases; 20.24\%). Coronary artery disease (829 cases; $45.47 \%$ ) abdominal aortic aneurysms (105 cases - 54 with rupture; 2.96\%), peripheral vascular (300 cases; $16.46 \%$ ), and others (271 cases: 14.87\%). Urgent thoracic and abdominal aortic aneurysm repair accounted for $23 \%$ respectively and the corresponding proportion for peripheral vascular surgery is $16 \%$. However, urgent surgery for acute coronary ischemia, valvular and congenital heart disease accounted for somewhat less than $60 \%$ for each group of these pathologies.

Systematic pre-operative diagnostic work-up is a recognized tool for procedure related risk assessment and superior management of diseases. However, hemodynamic instability and other time related events correlated with negative outcome, are the main driving forces for accelerated diagnostic pathways.
\end{abstract}

\section{Introduction}

Urgent surgery follows a path from resuscitation and stabilization of the patient with a management team, to preparation of the patient for surgery, and to post-operative and recovery proceduresall designed to deal quickly with the life-threatening situation. The first 120 minutes after arriving at an emergency room is a critical window for the survival from a serious heart disease. There is often little time or no possibility for extensive diagnosis or gathering patient's history. Decisions are made quickly about surgery, often without family members present [1].

Heart attacks are very effectively treated with urgent surgery depending upon the part of the heart affected, whether there is arterial blockage and overall health. Arrhythmias can develop, as well as stroke. The first 48 hours are the most crucial with cardiac events and whether there is immediate medical and surgical attention. Many cardiac surgeries result in bypass procedures. A higher death rate always is associated with bypass surgery done on an emergency basis. Patients with a positive troponin, always are correlated with a higher mortality rate after CABG surgery, than those ones with no increased troponin in blood [2]. The incidence of urgent heart bypass surgery is much higher in woman than in men, most probably due to lack of earlier cardiac care [3].

Patients with acute coronary syndromes who require urgent cardiac surgery with a persistent myocardial ischemia represent complex management challenges. The early administration of antiplatelet and antithrombotic drugs has improved overall sur- 


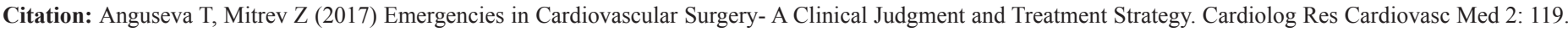
DOI: $10.29011 / 2575-7083.000019$

vival for patients with acute myocardial infarction, but to achieve maximal benefit, these drugs are given before coronary anatomy is known and before the decision to perform percutaneous coronary interventions or surgical revascularization has been made [4]. Even better according to the last $2011 \mathrm{ACCF} / \mathrm{AHA}$ guidelines, there is no necessarily for stopping with aspirin prior to operation. A major bleeding event secondary to these drugs is associated with a high rate of death in medically treated patients with acute coronary syndrome. For patients who do proceed to surgery, strategies to minimize bleeding include stopping of the anticoagulation therapy and considering platelet and/or coagulation factor transfusion, standard tranexamic acid and possibly recombinant-activated factor VIIa administration for refractory bleeding [1].

Mechanical hemodynamic support has emerged as an important option for patients with acute coronary syndromes in cardiogenic shock. For these patients, perioperative considerations include maintaining appropriate anticoagulation, ensuring suitable device flow, and periodically verifying correct device placement [4]. Urgent CABG for patients with ischemic mechanical complication (septum rupture, chordal rupture or free wall rupture) results with higher mortality rate up to $25 \%$ [2]. For patients with chest or back pain symptoms suggesting dissection of the aorta, as a standard it is provided access to transesophageal echocardiography, CT scanning using cardio protocol for visualization not only of the aorta but also of the coronary arteries, as well as all main branches from the aorta. Cardiologists and cardiovascular surgeons are available around the clock for management of the full spectrum of cardiac diseases.

Rupture of abdominal aneurysm results in death in about $50 \%$ of the cases due to kidney failure from shock or disrupted blood supply, or mesenteries ischemia. An untreated aneurysm is always fatal. Perioperative management in urgent cardiac surgery is challenging, because the general condition of the patient is often poor and only little preoperative information is available. In order to obtain an optimal surgical outcome, careful assessment of preoperative problems, prevention and detection of complications must be done without any delay [3]. Preoperative carotid duplex scan should be performed in every case to assess the stenoocclusive lesion or unstable plaque, which affects the surgical strategy (e.g. selection of arterial cannulation site and cerebral protection). Furthermore, this examination is necessary for final decision of cardiac surgery, whether it will be CABG or combination of CABG and carotidal vascular surgery (when patient has severe carotid stenosis and LMN stenosis, with unstable angina) (evidence level base IIB) [2]. Regional cerebral oxygen saturation (rSO2) must be monitored in all surgeries. If intraoperative drop in $\mathrm{rSO} 2$ is detected, administration of inotropic agents and increase in cardiopulmonary bypass flow is needed to maintain the mean blood pressure at higher level. Insertion of Intra-Aortic Balloon Pump (IABP) should be considered when $\mathrm{rSO}_{2}$ cannot be recov- ered with those procedures. We have to keep in mind that many of the patients undergoing urgent surgery are at high risk for coronary artery disease. If one cannot be weaned from cardiopulmonary bypass, coronary artery bypass grafting to a major branch may be performed.

Coronary angiography should be performed immediately when ST-T changes in Electrocardiogram (ECG) or chest symptoms appear in the postoperative period. Hesitation in making a decision will only jeopardize the situation.

\section{Material and Methods}

\section{Clinical setting}

The Special Hospital Zan Mitrev Clinic (Old Name: Surgery Fillip II) is a first private hospital for cardiovascular surgery in Macedonia, with 2 cardiovascular surgeons, 6 cardiologists, 40 ICU and 80 ward beds, equipped with one catheterisation laboratory and 128 slice CT scan with a 24/7 service level. The cardiology department has four experienced interventional cardiologists who perform $>750$ procedures a year, and a surgery team which performs more than 1500 surgeries per year.

\section{Patient}

From March 2000 to January 2012, we have analyzed a consecutive series of 10023 cases out of which 1823 underwent urgent procedures $(18.19 \%)$ in our hospital. The major selection criteria were emergency indications for surgery.

Main strategy of our hospital for accepting urgent cases is:

- 24 hours Urgent center, with urgent diagnostics (echocardiography, angiography as well as 128 MSCT scan)

- Well trained stuff at ICU

- Well organized transfusion department (30 min for prepared blood up to surgery)

- All urgent cases had been accepted in the urgent diagnostic center. With the help of the emergency team every patient had been stabilized and received all necessary diagnostic procedures.

- For the patients that need surgery, short time is needed from diagnostics, preoperative preparation and up to surgery (maximum 30 to $40 \mathrm{~min}$ )

- For the patient who needs stabilization, only 10 min are needed from the entrance up to ICU acceptance. Patient's urgency is determined according to the $2011 \mathrm{ACCF} / \mathrm{AHA}$ guidelines for aortocoronary bypass surgery, according to which the following groups of patients require urgent bypass- surgeries.

- Acute Myocardial Infarction (MI) 
Citation: Anguseva T, Mitrev Z (2017) Emergencies in Cardiovascular Surgery- A Clinical Judgment and Treatment Strategy. Cardiolog Res Cardiovasc Med 2: 119. DOI: $10.29011 / 2575-7083.000019$

- Acute MI with post infarction mechanical complications (ventricular septal defect, mitral valve insufficiently with chordal rupture or rupture of the free left chamber wall

- Cardiogenic shock

- Life threatening arrhythmia believed to be ischemic etiology

- Low cardiac output syndrome ischemic etiology

- Emergency CABG is recommended after failure of PCI in presence of ongoing ischemia

- Acute aortic dissection

- Abdominal aortic rupture

- Other (severe aortic stenosis, acute mitral insufficiently, acute aortic insufficiently).

- Acute peripheral vascular disease including acute stroke.

The preoperative patients' characteristics are listed in Table 1. The mean age was $69 \pm 7$ years and 982 patients were male. The atherosclerosis risk factors distribution was as follows: $65 \%$ active smokers, $56 \%$ suffering from systemic hypertension and $70 \%$ under treatment for hypercholesterolemia. A positive anamnesis of previous acute myocardial infarction was given in 966 cases (53\%) and 638 patients (35\%) had previous hospitalization during the week before surgery. Among them, 638 patients (35\%) developed signs of severe low cardiac output, 543 patients required a pre-operative Intra-Aortic Balloon Pump (IABP), and an urgent intubation with mechanical ventilation was necessary 234 times.

All patients underwent a preoperative cardiac assessment with a chest X-ray, an ECG, a standard coronary angiogram and a trans-thoracic echocardiogram as well as Doppler ultrasound of the carotidal arteries.

Patients with transthoracic ultrasound signs for acute dissection received immediately MSCT scan using a cardio protocol for estimation of the coronary arteries as well as other main branches of the aorta (truncus, carotidal, mesenteries, renal artery). By ultrasound echo evaluation the mean Left Ventricle Ejection Fraction (LVEF) rate was $27 \pm 8 \%$. Onsets of mitral valve dysfunction or regurgitation with left ventricular dilatation and/or focal dysfunction were important criteria for urgent coronary revascularization and pre-operative intra-aortic balloon pump insertion, if other therapies were contraindicated (i.e. thrombolysis and primary angioplasty).

MSCT scan was performed on all patients with aortic disease with tendency to precise the type of dissection, or aneurysm and to classify whether the patient is operable or not.

\begin{tabular}{|c|c|}
\hline \multicolumn{2}{|c|}{ Table 1: Baseline patients profile } \\
\hline Baseline patient profile ${ }^{*}$ & No. of Patients \\
\hline Total No of patients & 1823 \\
\hline Age (years) & $69 \pm 7($ range $57-79)$ \\
\hline Gender (M/F) & $982 / 841$ \\
\hline \multicolumn{2}{|l|}{ CCS angina class } \\
\hline III & $966(53 \%)$ \\
\hline IV & $565(31 \%)$ \\
\hline LVEF $(\%)$ & $27 \pm 8$ \\
\hline Hypertension & $1020(56 \%)$ \\
\hline Smoke & $1184(65 \%)$ \\
\hline Hypercholesterolemia & $1276(70 \%)$ \\
\hline Diabetes mellitus (I\&II) & $291(16 \%)$ \\
\hline Peripheral vascular disease & $638(35 \%)$ \\
\hline Prior myocardial infarction & $966(53 \%)$ \\
\hline Myocardial infarction $<7$ days & $638(35 \%)$ \\
\hline Preoperative IABP & $543(29 \%)$ \\
\hline $\begin{array}{c}\text { Preoperative mechanical ventila- } \\
\text { tion }\end{array}$ & $234(13 \%)$ \\
\hline Severe low cardiac output & $638(35 \%)$ \\
\hline Left main stump disease & $437(24 \%)$ \\
\hline Acute aortic dissection & $274(15 \%)$ \\
\hline Abdominal aortic rupture & $54(2.96 \%)$ \\
\hline Other (Acute Valvular Disease) & $271(14.78 \%)$ \\
\hline Peripheral vascular disease & $300(14.46 \%)$ \\
\hline${ }^{*}$ Stroke & $10(0.5 \%)$ \\
\hline \multicolumn{2}{|c|}{$\begin{array}{l}{ }^{*} \text { Data are presented as mean } \pm \text { SD or N }(\%) \\
\text { CCS: Canadian Cardiovascular Society Angina Class; New York Heart } \\
\text { Association; LVEF: Left Ventricular Ejection Fraction; MI: Myocar- } \\
\text { dial Infarction; IABP: Intra-Aortic Balloon Pump. }\end{array}$} \\
\hline
\end{tabular}

\section{Surgical Technique - Specificity}

Patients were prepared for surgery following the conventional guidelines and transoesophageal echocardiography was routinely performed intraoperatively. Through a median sternotomy, all patients were cannulated in the standard way except for patients who were necessary to be put on heart lung machine under reanimation. For these patients, we used femoral cannulation and right atrium for heart-lung circulation. Myocardium was preserved with continues warm cardioplegy, performed in ante grade and retrograde fashion.

In patients with acute dissection after cannulation of the right subclavian artery, and a temporary hitching of the brachiocephalic 
Citation: Anguseva T, Mitrev Z (2017) Emergencies in Cardiovascular Surgery- A Clinical Judgment and Treatment Strategy. Cardiolog Res Cardiovasc Med 2: 119. DOI: $10.29011 / 2575-7083.000019$

trunk, brain perfusion with 2-2.51 of blood, and 40mmHg pressure, on $28-30^{\circ} \mathrm{C}$ cooling is enabled. On such a way patient has sufficient brain perfusion while distal arch anastomosis is created.

For patients with ruptured abdominal aneurysm the crucial point was proximal clamping of the aorta. Following the incision of the aneurysm an occlusion is performed by placing two fingers on the proximal site of the normal aortic lumen. Afterwards, a proximal clamp is safely placed in order to ensure a bloodless surgery field. In all urgent surgeries, we employ cell-server, for re-using patient's own blood.

\section{Results}

Most frequent problems requiring urgent intervention were thoracic aortic aneurysms (369 cases; 20.24\%); coronary artery disease (829 cases; 45.47\%) abdominal aortic aneurysms (105 cases - 54 with rupture; $2.96 \%)$, peripheral vascular diseases ( 300 cases; $16.46 \%$ ), and others (271 cases: $14.87 \%$ ). Urgent thoracic and abdominal aortic aneurysm repair accounted for $23 \%$ respectively and the corresponding proportion for peripheral vascular surgery is $16 \%$.

However, urgent surgery for acute coronary ischemia, valvular and congenital heart disease accounted for somewhat less than $60 \%$ for each group of these pathologies.

\section{Coronary artery disease 829 cases; $45.47 \%$ of the urgent procedures}

Treatment strategy:

- Invasive monitoring, IABP or catecholamines if necessary.

- Urgent CABG for unstable patient's troponin negative.

- Acute myocardial infarction with complications (VSD, chordal rupture) -ICU stabilisation -invasive lines, IABP, catecholamines -after that surgery.

- Patients in cardiogenic shock- urgent CABG after stabilisation.

- Unstable patients with troponin I positive test- ICU stabilisation until biomarkers become negative, then surgery.

- Patients with ischemic dilative cardiomyopathy- preoperative ICU stabilisation and surgical intervention.

- All 829 high-risk patients were operated for urgent multiple myocardial revascularization.

- $722(87 \%)$ of them had been with ischemic left ventricle aneurysm.
- With urgent reanimation, under CPR, surgery was performed on 10 patients.

- With acute mitral regurgitation, due to acute mitral valve regurgitation (ischemic chordal rupture) 56 patients were operated. With ischemic VSD were operated 6 patients, one of them died.

- 4 patients entered urgently in the operating theatre due to ischemic rupture of the left chamber, 2 had been a first operation and 2 had been after surgery, due to reperfusion rupture of the antero-apical part of the left chamber.

- All 4 patients entered in the operating theatre under manual massage, with an urgent preparation of the operating table for less than 10 minutes. 2 survived, 2 died. (Survival rate 50\%).

The mean number of graft/patient was $2.9 \pm 0.6$ and the Left Internal Mammary Artery (LIMA) was used in 827. In two cases, the mammary artery was not used because the time spent to harvest the mammary artery would have endangered the patient's hemodynamic stability. The mean CPB time was $84 \pm 19$ minutes and the mean total operative time was $188 \pm 36$ minutes. $722(87 \%)$ of CABG patients received a left ventricle reconstructive surgery.

Survival rate was 93.5 with 54 dead patients (main reason for death was low cardiac output). CVVHDF was performed in 10 patients. Pre-operative IABP was implanted in 543 (65.5\%) patients. Percutaneous tracheostomy in 15 patients and percutaneous gastrostomy in 25 patients, $13(1.57 \%)$ patients developed sepsis. Mesenteric ischemia with abdominal surgery was performed in $25(3.02 \%)$ patients. Average in hospital stay was $38.5 \pm 9.8$ days.

\section{Thoracic aortic aneurysm 369 cases, $20.24 \%$ of the ur- gent procedures}

\section{Treatment strategy:}

\section{-invasive monitoring, biochemistry}

-for patient without any cons cess, or with extremely high negative basic excess, with signs for mesentherial ischemia and bowel suffering, operation is not recommended, because of the terminal stadium of the disease

\section{- all other cases urgent surgery}

From the 369 (20.24\%) patients with thoracic aortic aneurysm, 95 had been patients with chronic aortic aneurysm and 274 with acute dissection. 
Citation: Anguseva T, Mitrev Z (2017) Emergencies in Cardiovascular Surgery- A Clinical Judgment and Treatment Strategy. Cardiolog Res Cardiovasc Med 2: 119. DOI: $10.29011 / 2575-7083.000019$

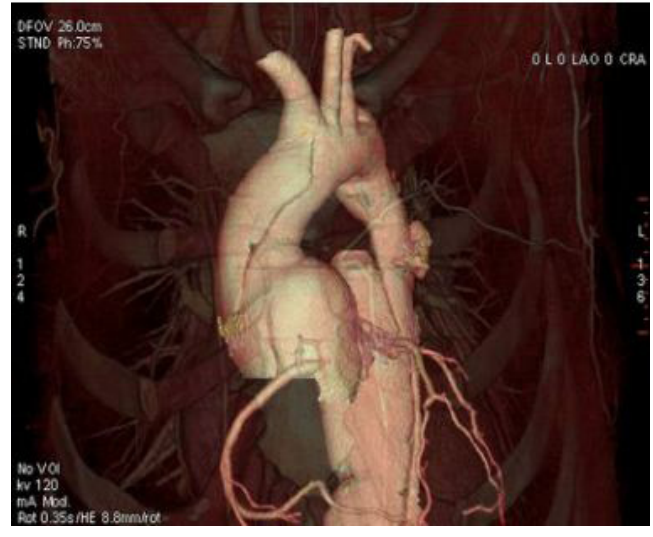

Figure 1: Acute Aortic Dissection of The Ascending Aorta.

Survival rate was $94.9 \%$ with 19 dead patients. 3 patients had been treated with continuous reno-renal replacement therapy (CVVHDF) due to acute renal insufficiency, 6 received percutaneous tracheotomy (long time ventilation $24 \pm 4-5$ days). Percutaneous gastrostomy for feeding was performed in 5 patients. Average in hospital stay was $38 \pm 8-9$ days. 5 patient who had extremely deep and refractory negative $\mathrm{BE}>-10$ without any conscious, and mesenterial ischemia with a bowel suffering died after surgery because of terminal metabolic changes.

\begin{tabular}{|c|c|c|}
\hline Type of Surgery & Aortic Dissection & Aortic Aneurysm \\
\hline Tyrone David & 38 & 34 \\
\hline $\begin{array}{c}\text { Suspension of the } \\
\text { aortic annulus }\end{array}$ & 64 & 27 \\
\hline $\begin{array}{c}\text { Reinforcement of the } \\
\text { free margine of the } \\
\text { semilunar leaflet }\end{array}$ & 15 & 17 \\
\hline $\begin{array}{c}\text { Replacement of the } \\
\text { aortic valve }\end{array}$ & 34 & 7 \\
\hline Graft Interponat & 56 & \\
\hline $\begin{array}{c}\text { Reimplantation of the } \\
\text { main vessels of the } \\
\text { head }\end{array}$ & 67 & \\
\hline
\end{tabular}

Table 2

Abdominal aortic aneurysms (105 cases - 54 with rupture; $2.96 \%$ )

Treatment strategy:

$$
\begin{array}{ll}
- & \text { Invasive lines } \\
\text { - } & \text { Volume supplying } \\
\text { - } & \text { Urgent surgery }
\end{array}
$$

54 (2.96\%) patients with rupture of the abdominal aorta had been urgently entered in the operating theatre. Time from entrance to operation was less than 30minutes. 35 patients got infrarenal aortic replacement with an Albograft interponat, 10 were with aorto-biiliacal, and 5 with aorto-iliacal replacement.

In the postoperative period only one patient died due to multi-organ failure. 2 patients were placed on continuous reno-renal replacement therapy due to acute renal failure. One patient had combined surgery, distal aorta replacement and collonostoma due to mesenteric gangrene (a. mesenterica inferior occlusion). 3 patients got abdominal surgery due to mesenteric ischemia (a. mesenterica inferior). Media in hospital stay was $22 \pm 12$ days. 5 patients got percutaneous tracheotomy due to long time ventilation (20 \pm 3 -5days $)$

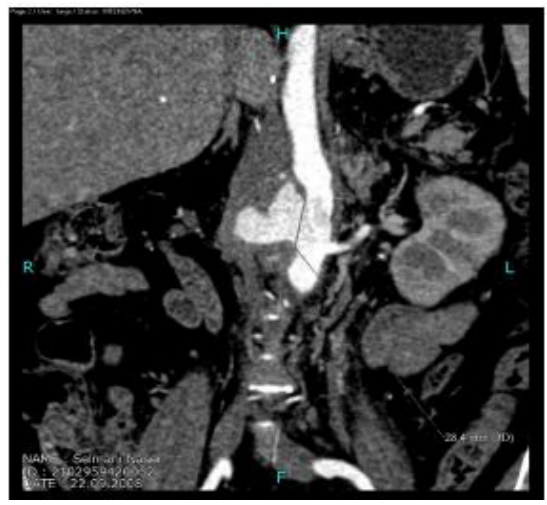

Figure 2: Acute Rupture of the Abdominal Aorta.

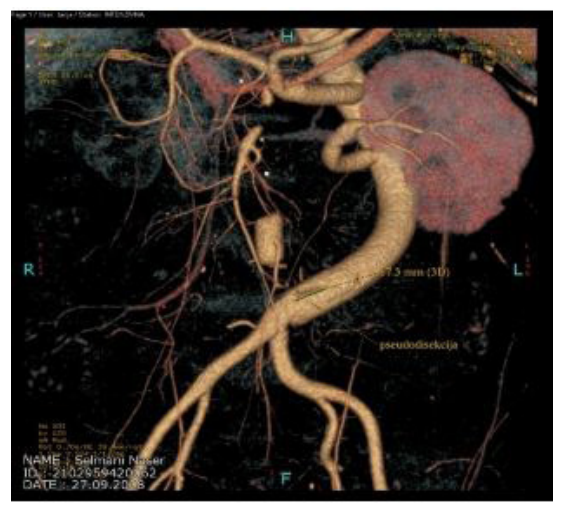

Figure 3: Control CT Scan after Surgery.

\section{Peripheral vascular ( 300 cases; $16.46 \%$ of the urgent} procedures)

Treatment strategy:

-invasive lines

-volume supplying

-anticoagulant therapy

-urgent surgery

All patients had been immediately diagnosed by 64 MSCT scan, urgent surgery was performed in the next 1 hour after acceptance in our unit. 3 patients needed urgent re-operations (in the next 2 days) due to graft occlusion. The in-hospital stay was 5-6 $\pm 1-2$ days. 
Citation: Anguseva T, Mitrev Z (2017) Emergencies in Cardiovascular Surgery- A Clinical Judgment and Treatment Strategy. Cardiolog Res Cardiovase Med 2: 119. DOI: $10.29011 / 2575-7083.000019$

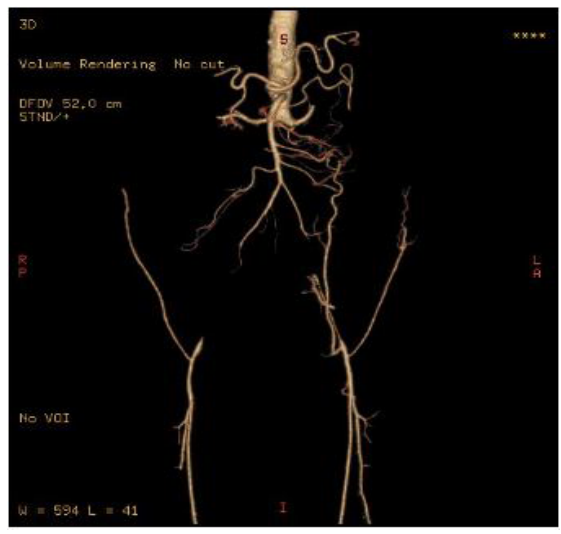

Figure 4: Leriche Syndrome.

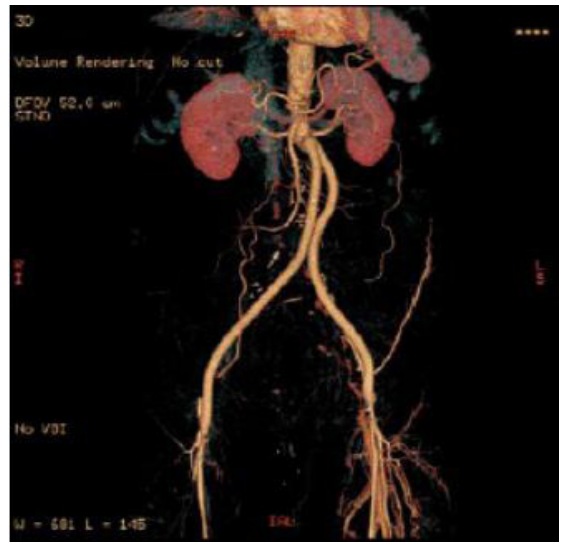

Figure 5: Control CT Scan after Surgery.

Ten patients from the vascular group had been operated in 24 to max 72 hours after getting stroke, one of them was in coma. Two patients died, 8 had been completely recovered and turned back in a normal life, including the patient who was in coma, but he had slight left sided hemiparesis with psychological instability. Survival rate $99.33 \%$

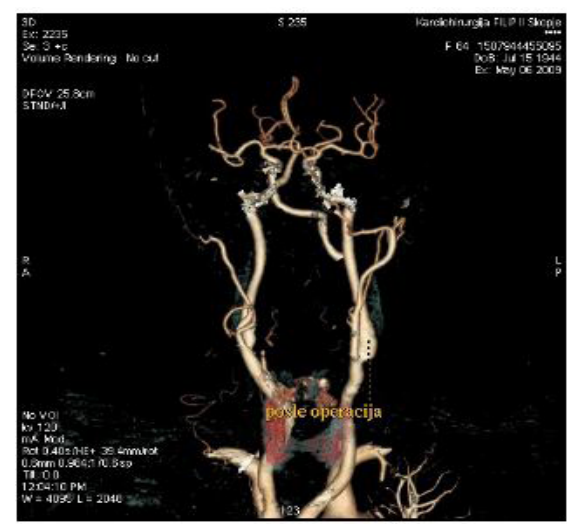

Figure 6: Acute Occlusion of Right ACI.

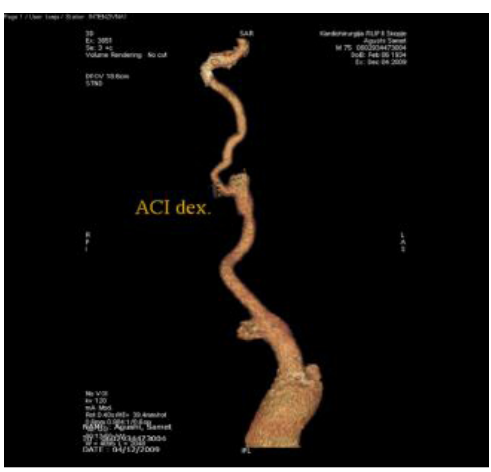

Figure 7: Control CT Scan after Surgery.

\section{Others (271 cases: $14.87 \%)$}

Treatment strategy:

-invasive lines, catecholamines, ICI stabilization

-appropriate operation

Urgent aortic valve surgery - 54 patient's due to severe aortic stenosis (terminal valvular disease) (3 patients died pre-operatively, 2 died postoperatively) Urgent aortic valve surgery due to aortic insufficiency gr IV -65 patients (1 patient died postoperatively). Extirpation of myxoma - 116 cases (survival rate 100\%). 35 patients with acute rupture of the chorda of the mitral valve

1 patient with tumor in the right atrium.

The cumulative results are presented in the next Table 3.

\begin{tabular}{|c|c|}
\hline \multicolumn{2}{|c|}{ Postoperative results* } \\
\hline No. of patients & 1823 \\
\hline Hospital mortality & $82(4.50 \%)$ \\
\hline Ventilation time (hours) & $26 \pm 37$ (range $7-168)$ \\
\hline Pre-operative IABP & $543(29.69 \%)$ \\
\hline Total bleeding $(\mathrm{mL})$ & $1340 \pm 903$ \\
\hline Re-exploration for bleeding & 7 \\
\hline Myocardial infarction & 1 \\
\hline Postoperative LVEF (\%) & $34.4 \pm 8.5$ \\
\hline Low cardiac output & $50(2.7 \%)$ \\
\hline Transitory acute renal failure & $15(0.82 \%)$ \\
\hline Sternal infection & $9(0.5 \%)$ \\
\hline Intensive care unit stay (days) & $24.4 \pm 6.4$ (range $3-45)$ \\
\hline Hospital stay (days) & $28 \pm 6.7$ (range $8-34)$ \\
\hline $\begin{array}{l}{ }^{*} \text { Data are presented as mean } \pm \\
\text { loon Pump; CK-MB: LVEF }\end{array}$ & $\begin{array}{l}\text { (\%): IABP: Intra-Aorti } \\
\text { tricular Ejection Fracti }\end{array}$ \\
\hline
\end{tabular}

Table 3 


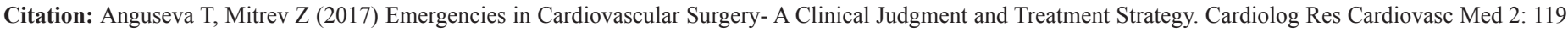
DOI: $10.29011 / 2575-7083.000019$

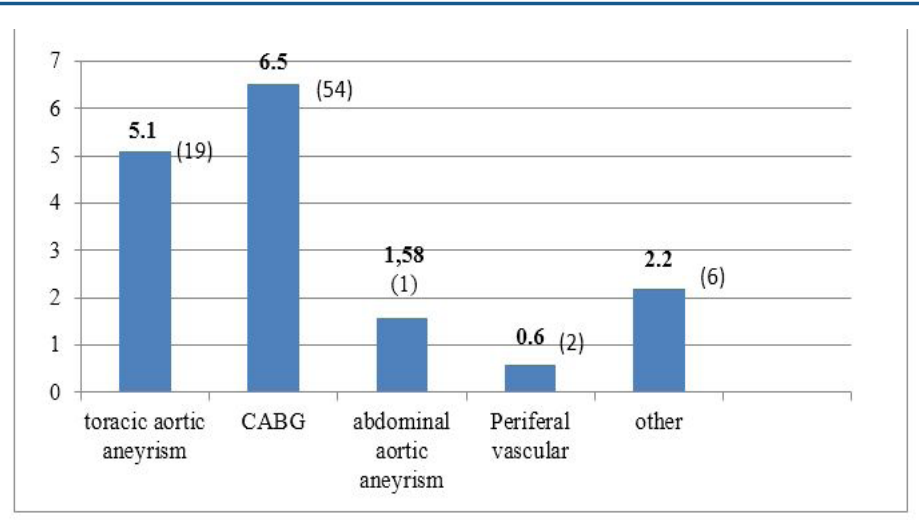

Graph 1: Mortality Rates in the Different Groups.

Patients were followed up for one to 12 years after surgery: they all had a standard trans-thoracic echocardiogram and a clinical examination. Excluding the 35 patients who died following cardiac arrest, all 1706 survivors have an acceptable quality of life with a mean LVEF of $36 \pm 11.8 \%$. There were 25 cardiac re-operations (in the group with CABG surgery), major neurological events or acute myocardial infarctions, although one patient required an Implantable Cardiac Defibrillator (ICD) to prevent severe electrical dysfunctions originating from their ischemic cardiomyopathy. Follow-up details are listed in Table 4.

\begin{tabular}{|c|c|}
\hline \multicolumn{2}{|c|}{ Follow-up results* } \\
\hline Mean follow-up time (months) & $2 \pm 144$ \\
\hline No. of patients & 1744 \\
\hline Internal cardiac defibrillator & 1 \\
\hline Cardiac death & $35(1.91 \%)$ \\
\hline LVEF (\%) & $36 \pm 11.8$ \\
\hline \multicolumn{2}{|c|}{ Data are presented as mean \pm SD or N (\%) } \\
LVEF: Left Ventricular Ejection Fraction. \\
\hline
\end{tabular}

\section{Table 4}

\section{Discussion}

Urgent cases in cardiovascular surgery ask for well-trained team including experienced cardiovascular surgeon. Urgent diagnostics is very important for life-saving treatment. Well organized urgent center gives a chance to emergency patients to be accepted, stabilized, receive the right diagnosis, and on time surgery, with a low mortality rate. In addition, improvements in surgical technique and postoperative care mean that cardiac arrest in the surgical intensive care is much less common. As a result, the staff is less familiar with emergency chest reoperation when such an arrest occurs $[5,6]$.

The optimal treatment for patients presenting with unstable angina, acute coronary syndrome, onset of myocardial infarction or severe left ventricular dysfunction and carrying a diffuse multivessel coronary artery disease is still controversial. In particular, patients with severe multi-vessel coronary artery disease or main stump disease, presenting comorbidities that contraindicate the thrombolysis, or showing signs of acute and severe left ventricular dysfunction with low cardiac output requiring urgent mechanical circulatory support, can derive big benefits from emergency onpump multiple myocardial revascularization. Nevertheless, the standard surgical technique, with cardioplegic arrest and cardiopulmonary bypass, may not be the ideal solution in this cohort of very high-risk and unstable patients: in particular, cardioplegic arrest and aortic cross clamping have been isolated as independent surgical risk factors for high-risk patients suffering from acute coronary syndrome and severe cardiac dysfunction, while the avoidance of cardiopulmonary bypass does not confer significant clinical advantages, as suggested by recent reports [7-11]. In particular, our patients were not suitable for alternative non-surgical treatments, they were operated in the shortest delay, and they were preoperatively treated with IABP and/or low doses of inotropic drugs in order to achieve a certain degree of hemodynamic stability, when needed. The biggest benefits deriving from the on-pump beating heart technique were the reduction of the hemodynamic instability caused by surgical manipulations, the absence of global myocardial ischemia during aortic cross-clamping time and the absence of reperfusion after cardioplegic arrest. It is important decision when to perform CABG surgery in patient with subacute myocardial revascularization. It is well known that reperfusion effects of the left chamber myocardium can result with a myocardial rupture and need for urgent re-sternotomy and re-operation with a left chamber ventriculoplasty as it was shown in our two cases. In conclusion, one of the main problems in patients undergoing emergency $\mathrm{CABG}$ remains the myocardial protection and the side effects coming from the transitory myocardial ischemia during arrested heart surgery (possibly due to myocardial edema) [1,12]. Pre-operative ICU stabilization even in the urgent cases showed that the results from performed surgery are close to those one like in an elective case.

The in-hospital mortality rate for patients diagnosed with thoracic aortic dissection is $26 \%$ [1]. Our low rate of mortality rate was result from on time diagnostic, and surgical technique, thanks to which patients had less postoperative complications (no severe hypothermia coagulopathy resulting).

Currently, there are no national guideline-recommended diagnosis-to-treatment times for aortic dissection-as in the less than 90 minutes for door-to-balloon times for acute MI. However, if the diagnosis is specifically made prior to arrival, the average goal is approximately 90 minutes from time of presentation according to Clarian (Indiana University Health organization, specialized in urgent surgery).

Approximately two out of three patients with a ruptured AAA die before they even reach a hospital. For those patients who actually make it to the hospital and undergo surgery, there is a 
Citation: Anguseva T, Mitrev Z (2017) Emergencies in Cardiovascular Surgery- A Clinical Judgment and Treatment Strategy. Cardiolog Res Cardiovasc Med 2: 119. DOI: $10.29011 / 2575-7083.000019$

50 to 70 percent mortality rate associated with a ruptured AAA. Despite the need for urgent treatment, there is no standardized, guideline-recommended timeline from ruptured AAA diagnosis to treatment.

"The only reason these patients don't die immediately is because the retroperitoneum, which separates the major blood vessels from the bowels, is thick and tough enough to hold a small leak in place for a while. However, if the patient's blood pressure rises and causes rupture or pumping of blood into the free abdominal cavity, the patient will likely bleed to death before we can rush the patient to surgery [13]."

Once patients are diagnosed in the hospital setting, the goal is to keep a patient's blood pressure low to avoid a free rupture, and transport them quickly to the operating room, still there are a lot of controversies for the patients with acute episode of stroke. Our experiences showed that surgical revascularizations return bigger part of cerebral function and decrease the degree of invalidity in the patient.

\section{Conclusion}

In conclusion, although further reports and randomized clinical trials are necessary to compare results coming from different surgical strategies undertaken to treat such a subgroup of highrisk patients, we strongly believe that, following reported data and looking closely to our surgical activity in this field, that on time diagnosis, emergency prep of the patients allows to choose right surgical strategy for the patient and to perform the strategy on time to get a better clinical results with a better survival rate.

The decision-making process was an "Intensive, large-scope exercise" due to multidisciplinary team required to treat these patients.

\section{References}

1. Circ Cardiovasc Qual Outcomes (2010) 3: 424-430.

2. ACCF/AHA Guidelines for CABG (2011).
3. Gaudino M, Glieca F, Alessandrini F, Nasso G, Pragliola C, et al. (2004) High risk coronary artery bypass patients: incidence, surgical strategies and results. Ann Thorac Surg 77: 574-580.

4. Birdi I, Chaudhuri N, Lenthall K, Reddy S, Nashef SA (2000) Emergency reinstitution of cardiopulmonary bypass following cardiac surgeryoutcome justifies the cost. Eur J Cardiothorac Surg 17: 743-746.

5. Pottle A, Bullock I, Thomas J, Scott L (2002) Survival to discharge following open chest cardiac compression (OCCC). A 4-year retrospective audit in a cardiothoracic specialist centre-Royal Brompton and Harefield NHS Trust, United Kingdom. Resuscitation 52: 269-272.

6. Nolan J, Baskett P (2005) European Resuscitation Council Guidelines for Resuscitation 2005 Resuscitation 67(Suppl 1): S1-S190.

7. Légaré JF, Buth K, King S, Wood J, Sullivan J, et al. (2004) Coronary bypass surgery performed off pump does not result in lower in-hospital morbidity than coronary artery bypass grafting performed on pump. Circulation 09: 887-892.

8. Van Belleghem Y, Caes F, Maene L, Van Overbeke H, Moerman A (2003) Off-pump coronary surgery: surgical strategy for the high-risk patient. Cardiovasc Surg 11: 75-79.

9. Folliguet TA, Philippe F, Larrazet F, Dibie A, Czitrom D (2002) Beating Heart Revascularization with Minimal Extracorporeal Circulation in $\mathrm{Pa}-$ tients with a Poor Ejection Fraction. Heart Surg Forum 6: 19-23.

10. Edgerton JR, Herbert MA, Jones KK, Prince SL, Acuff T (2004) Onpump beating heart surgery offers an alternative for unstable patients undergoing coronary artery bypass grafting. Heart Surg Forum 7: 8-15.

11. Task Force on Aortic Dissection (1988) European Society of Cardiology Diseases of the Aorta and Trauma to the Aorta and Heart last published 2001. Br J Surg 75: 733-736.

12. Mackay JH, Powell SJ, Osgathorp J, Rozario CJ (2002) Six-year prospective audit of chest reopening after cardiac arrest. Eur J Cardiothoracic Surg 22: 421-425.

13. A Report of the American College of Cardiology Foundation/American Heart Association Task Force on Practice Guidelines. J Am Coll Cardiol58: 2020-2045 @2011 by the American College of Cardiology Foundation. 